\title{
Research on the Key Technology of RFID and Its Application in Modern Logistics
}

\author{
Lei Liu \\ Sichuan College of Architectural Technology, Deyang, Sichuan, 618000, China
}

\begin{abstract}
The paper studies communication protocol, the structure of the circuit, antenna design of radio frequency identification technology (RFID), and puts forward a scheme based on IOT application: RFID logistics tracking system. Finally, the paper studies the logistics distribution center information management model from three aspects of the system design objectives, system function analysis and system architecture design based on RFID.
\end{abstract}

Keywords-RFID; logistics distribution center; information management system.

\section{INSTRUCTION}

The accelerated process of economic globalization makes the enterprise be in a full range of core competitiveness and creating in many areas of cost, technology, management and supply chain jockeying, generally they pay attention to the supply chain operation and management of strategic planning, warehouse management, distribution center planning and the planning of logistics distribution center planning. With the rapid changes in the types of goods, quantity of import and the enterprise supply chain logistics operation and the growing customer demand, the traditional bar code technology as the main support to the logistics distribution center information management model has been unable to effectively support the entire supply chain dynamic, agile reaction, and the radio frequency identification technology that RED is under development and get mature application technology in important networking, remodeling and renovation on the basis of information system for logistics distribution center for the formation of more efficient, more rich in response to customer demand to the ability of flexible. Based on this, this paper based on RED technology, according to the supply chain operation mechanism of logistics distribution center of the remodeling and design of information management system for logistics distribution center.

\section{THE EXISTING PROBLEMS OF LOGISTICS DISTRIBUTION CENTER INFORMATION AND THE ADVANTAGE OF RFID}

\section{A. The disadvantages of bar code technology}

The information management of the traditional logistics distribution center is largely the goods information reading and recognition based on the application of bar code, bar code technology has also made important contributions to the logistics distribution center information once. But with the new application requirements of the construction practice in-depth and informational logistics distribution center, it existed more and more limitations and problems. The vulnerability of the first bar code makes the compatibility and poor readability, resulting goods information and related logistics information have low acquisition rate and accuracy rate in the logistics distribution center, order data is not standard, inventory cycle is longer and the inventory of goods have higher loss; second, the bar code technology cannot effectively meet the distribution of information resources sharing under the environment of supply chain logistics, cannot provide good technical support for business coordination of relevant subject logistics and distribution business in question, so that the logistics distribution of distribution capacity relative to the dynamic change of customer demand lacks the elasticity and flexibility.

\section{B. The advantage of RFID in logistics distribution center information}

Radio frequency identification technology is that RFID built in radio technology, has many advantages in the read information of the goods and recognition, such as can be read not visible goods label, it can simultaneously fast read multiple goods label information without exact alignment read, write and modify, at the same time in the data security and, there are a lot of good performance. Logistics information system based on RFID can be implemented efficiently reduce the operation cost and the operation efficiency promotion; can provide a unique code for each piece of goods in stock goods, to prevent counterfeit behavior; greatly enhance the logistics information goods delivery process accuracy can effectively realize the information sharing; the link in the supply chain upstream and downstream members; goods can be the current logistics status and spatial patterns of fast storage $\mathrm{Bu}$ to. Therefore, the logistics management information system can realize the logistics distribution in the realization of logistics information accurately on the fast and flexible response based on RFID.

\section{THE KEY CIRCUIT DESIGN OF RFID READER HARDWARE}

The RFID logistic tracking mainly consists of three subsystems (or module): RFID card reader, wireless / serial communication module, the Internet of things system. The relation between them is as shown in Fig.1. 


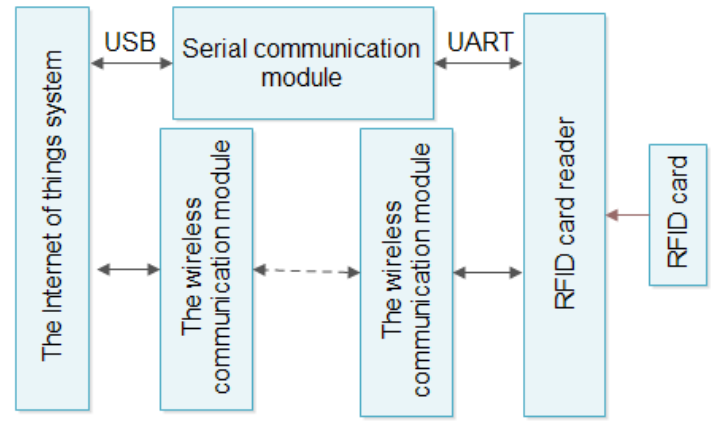

Figure 1 . The structure of the system diagram

\section{A. Design of read write device for RFID}

RFID card reader is as the system's RFID read-write terminal, responsible for receiving, sent analytical data packets through IOT system, control work of wireless/ serial communication module to read and write, and give feedback to the computer system for RFID card. RFID card reader, wireless / serial communication module and RFID card relative to the host computer can be collectively referred to as the slave machine. Block diagram of the whole system of the lower position machine is as shown in Fig.2.

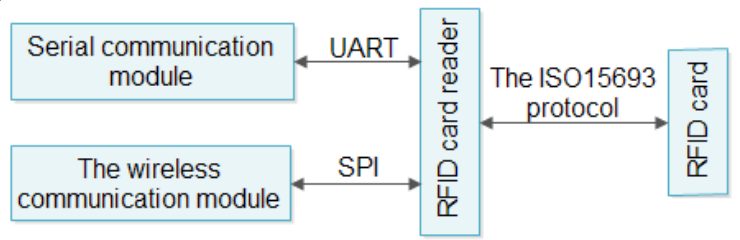

Figure 2. The whole block diagram of the slave system

\section{B. The application of SLRC400 circuit design}

Modulation and demodulation chip select RFID SL RC400 integrated chip of NXP Company, SLRC400 is a highly integrated $13.56 \mathrm{MHz}$ passive communication chip series. The chip has a set of modulation and demodulation in one, at the same time, it support h.CODE1 and IS015693 of each layer communication protocol. The communication of its internal transmitter can drive an external design and distance of $100 \mathrm{~mm}$ antenna.

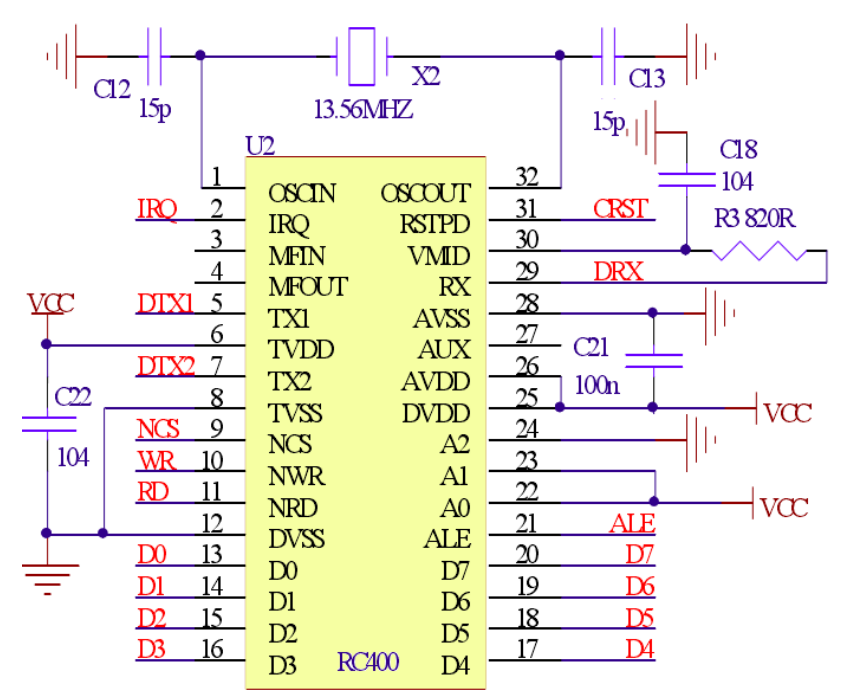

Figure 3. The peripheral circuits diagram of RC400 chip

\section{The design of the antenna coil}

As shown in Fig.4, the DTX 1 /DTX2 SL antenna are respectively connected to the RC400 chip driver pin, DRX is the signal receiving end connected to the signal of SL RC400 chip receives a pin.

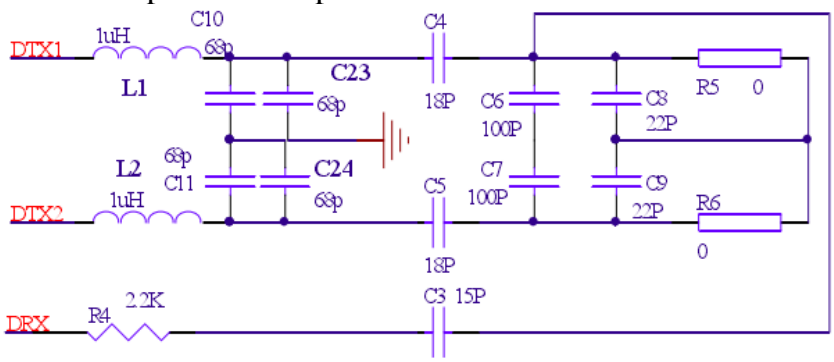

Figure 4. RFID antenna circuit diagram

Circuit parameters can be designed as shown in Fig.5.

\begin{tabular}{ll}
\hline Component & Value \\
$L_{0}$ & $1 u \mathrm{H}(\mathrm{e} . \mathrm{g}$. TDK NL322522T-1ROJ) \\
\hline$C_{01}$ & $68 \mathrm{pF}$ each (Ceramic NPO, tolerance $\leq \pm 2 \%)$ \\
$C_{02}$ & $56 \mathrm{pF}$ each (Ceramic NPO, tolerance $\leq \pm 2 \%)$ \\
\hline$C_{1}$ & $12 \mathrm{pF}$ each (Ceramic NPO, tolerance $\leq \pm 2 \%)$ \\
\hline$C_{21}$ & $82 \mathrm{pF}$ each (Ceramic NPO, tolerance $\leq \pm 2 \%)$ \\
\hline$C_{22}$ & $6.8 \mathrm{pF}$ each (Ceramic NP0, tolerance $\leq \pm 2 \%)$ \\
\hline$C_{3}$ & $1 \mathrm{nF}($ Ceramic NP0, tolerance $\leq \pm 10 \%)$ \\
\hline$C_{4}$ & $100 \mathrm{nF}($ Ceramic X7R, tolerance $\leq \pm 10 \%)$ \\
\hline$R_{1}$ & $2.2 \mathrm{k} \Omega$ \\
$R_{1}$ & $820 \Omega$ \\
$R_{S}$ & $4.7 \Omega$ \\
\hline
\end{tabular}

Figure 5. Select the parameter matching of the antenna 
The matching parameter of antenna is as shown in Fig.5 lists, S11 parameters of antenna measurement made RFID coil antenna and experiment as shown in Fig.6, the obtained waveforms signal is as shown in Fig.7.

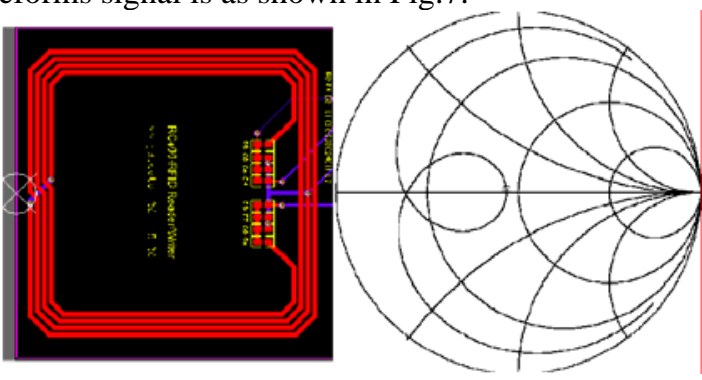

Figure 6. Antenna structure and its S11 parameter

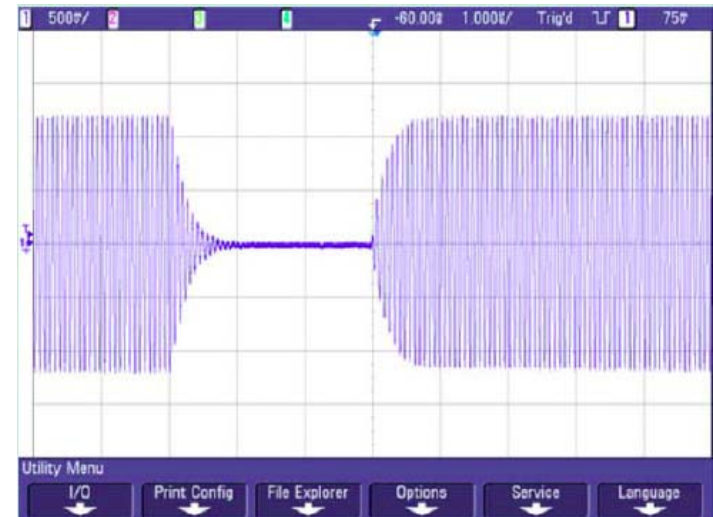

Figure 7. RFID signal waveform measured on the antenna (424kb/s)

\section{Communication protocol between upper computer and $R F I D$ reader}

Each RFID reader communicate with a host computer through RS232 serial port. In order to realize normal communication between computer and reader, communication both sides must have the same parameter setting. The host computer to a certain protocol format and reader communication. The protocol frame is:

\begin{tabular}{|c|c|c|c|c|c|c|c|}
\hline 1 & 2 & 3 & $4 \ldots \mathrm{n}-2$ & \multicolumn{2}{|r|}{$n-1$} & \multicolumn{2}{|c|}{$n$} \\
\hline $\begin{array}{l}\text { Frame } \\
\text { length =n }\end{array}$ & Channeling & $\begin{array}{l}\text { Control } \\
\text { command }\end{array}$ & $\begin{array}{l}\text { Protocol } \\
\text { data }\end{array}$ & \multicolumn{2}{|c|}{$\begin{array}{l}\text { The most high } \\
\text { parity check code }\end{array}$} & \multicolumn{2}{|c|}{$\begin{array}{l}\text { The low parity } \\
\text { check code }\end{array}$} \\
\hline \multicolumn{8}{|c|}{ Read write device $\rightarrow$ The host computer } \\
\hline 1 & 2 & 3 & 4 & $5 \ldots \ldots n-2$ & \multicolumn{2}{|l|}{$n-1$} & $\mathrm{n}$ \\
\hline $\begin{array}{c}\text { Frame } \\
\text { length }=n\end{array}$ & Channeling & $\mid \begin{array}{c}\text { Control } \\
\text { command }\end{array}$ & State & $\begin{array}{c}\text { Protocol } \\
\text { data }\end{array}$ & \multicolumn{2}{|c|}{$\begin{array}{l}\text { The most high } \\
\text { parity check code }\end{array}$} & $\begin{array}{c}\text { The low parity } \\
\text { check code }\end{array}$ \\
\hline
\end{tabular}

\section{ANALYSIS OF LOGISTICS AND DISTRIBUTION CENTER MANAGEMENT SYSTEM BASED ON RFID}

Fig.8 shows the composition of logistics distribution center information system and function module structure based on the supply chain for retailers service, the logistics distribution center information management system oriented retailer service will be divided into five modules, namely the customer management system, order management system, inventory management systems, distribution management system and financial management system.

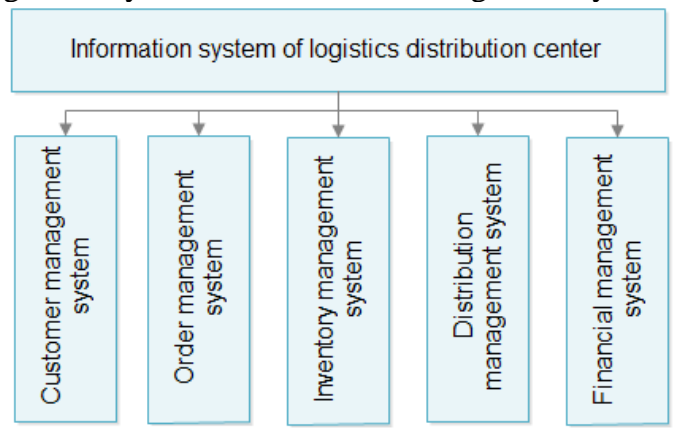

Figure 8 . The system function and module structure

The main function of customer management module in the system including: contact and information communication and raw materials, materials suppliers, the carrier of the cargo, customers and other supply chain node enterprises, the external parts of the supply chain and logistics distribution center of the internal business functions organically linked together, so as to promote the sharing of information resources and to enhance the value of, and based improve the operation of the whole supply chain efficiency.

The main function of order management modules in the system include: analysis of goods delivery order to the customer demand, and on the subsequent sectors such as inventory information, customer credit qualification, management, invoice of goods sorting and classification distribution processing to how to make the execution of the order decision. Order management can achieve very fruitful help supply chain related enterprises optimization, shorten the order fulfillment cycle, and improve the performance of the order inventory management performance, thus speeding up the warehouse goods turnover rate.

The main function of inventory management system module includes: covers from the storage of goods until the start of delivery of goods for all link ratio, including goods shelves, sorting, processing, packaging, picking route, workload, picker division of responsibilities, inventory level control etc., at the same time, the use of some advanced methods and ideas of the inventory management control to provide the level of inventory management.

The main functions of distribution management system module includes: goods transportation vehicle scheduling, scattered cargo carpooling and self-contained, transportation route optimization and selection, goods in transit tracking and monitoring, the views of customers complaint handling and transportation cost calculation and control.

The main function of the financial management module of the system include: measurement, distribution cost expenses payable receivable records and registration, invoice payment issue, goods reconciliation documents collation and collection, payment and other financial verification management etc.. 


\section{THE SYSTEM ARCHITECTURE DESIGN}

(1) Hierarchy. Information systems of the logistics distribution center is divided into 3 levels, namely the data layer, business layer and decision layer, each layer and include the contents of the Tab.1. Business data layer storage data of the whole system; business layer treatment on report information derived from a database, contract information and bill information calculation processing; commercial application refers to income from business process information is applied to the actual distribution business, such as warehouse operation plan, transportation route selection, inventory management implementation; system control refers to the automation control for smart device of the logistics operation, feedback to the situation to complete the action instruction and execution results; the decision layer is refers to assist the senior management of logistics strategy and planning through making construction analysis model of logistics distribution operation.

TABLE .I. THE HIERARCHICAL STRUCTURE OF THE SYSTEM

\begin{tabular}{l|l}
\hline Decision-making layer & Decision system \\
\hline \multirow{4}{*}{ Business layer } & Decision making system \\
\cline { 2 - 2 } & Business processing \\
\cline { 2 - 2 } & Commercial application \\
\cline { 2 - 2 } & System control \\
\hline Data layer & Database \\
\hline
\end{tabular}

(2) The system architecture from the bottom to the upper layer sequentially comprises the following parts, namely system of environmental safety, information infrastructure, support platform, logistics platform, logistics service application, information display, the client and the external link system.

System security environment can protect the system from external threats, attacks and illegal intrusion, so as to ensure the safe and stable operation of the whole system;

The information infrastructure constitute the whole system operation platform, which mainly consists of a series of RFID equipment, bar code labels, GPS equipment, network hardware, operating system, database system and related network protocols;

The role and function of supporting platform is the efficiency and performance of the system, it can optimize the performance of the system, system development and maintenance, and reliable operation of the system management and related application operation support;

The development of logistics service platform can be related to logistics information system and application software to provide the auxiliary function maintenance, thus simplifying the related application development process and task;

The core of the information management system is the composition of logistics service application, it is responsible for the entire system of logistics service core business logic, a variety of customized logistics operation process, and through the establishment of a business unit calls to perform various application;

Information display mainly for a variety of commercial application terminal, formulate detailed information expression and display mode for it, will be a variety of logic in the application of logistics service calculation results submitted information interaction to the client system and is responsible for the client and server are;

The client is to carry out information interaction between client and server media, including all kinds of browsers, mobile terminal equipment, the Java client; external link system and logistics information management system for data exchange and sharing, mainly including bank support gateway, client authentication center and supply chain partner information system.

In the construction of logistics distribution center information management system for retail services, according to the characteristics of the retail logistics service distribution of goods, generally including the technical architecture of various types, which integrated $\mathrm{B} / \mathrm{S}$ architecture model based on Web Service based on the most common.

\section{CONCLUSION}

Logistics distribution center information management system can help the whole logistics supply chain that can built up supply chain initiative feedback mechanism based on RFID, to achieve real time management inventory goods, so as to improve the logistics distribution center operation efficiency and enhance core competitiveness. According to the logistics distribution center for retailers to provide logistics services, using network and information thinking frame design the logistics management information system based on RFID technology, aimed at the realization of fine management for the logistics distribution center.

\section{REFERENCES}

[1] Xie Yong, Wang Hongwei. Automatic storage management system and its application based on Internet of things [J]. Material flow technology, 2010, (4).

[2] Yu Xu. Internet of things logistics management system based on RFID electronic label [J]. Micro computer information. 2009, (2).

[3] $\mathrm{Lu} \mathrm{Li}$, Xie Jiangang. Application of RFID analysis and the Countermeasures of technology in retail industry [J]. computer generation, 2010, (12).

[4] Xu Dan, Wang Tiening. Application of RFID in logistics distribution center [J]. Logistics technology, 2009, (9).

[5] Jiang Yajun, He Ping, Zhao Huiqun, Ceng Shiyuan. Internet of things based on EPC research review [J]. Guangdong communication technology, 2009, (8). 